\title{
Experience of Creating Digital Twins as a Result of Monitoring the Health of Industrial Personnel
}

\author{
Leonid I. Baranov 1[ORCID 0000-0002-1376-6844], \\ Olga A. Tikhonova $\left.{ }^{1 *[O R C I D} 0000-0002-2255-4667\right]$, \\ Alexey N. Tsarev 1[ORCID 0000-0001-6412-8247], \\ Nikolay M. Tverdynin 2[ORCID 0000-0003-0678-0768], \\ Nadezhda I. Grishakina 3[ORCID 0000-0002-1693-8840]
}

\author{
${ }^{1}$ Russian State Research Center - Burnasyan Federal Medical Biophysical Center, Federal Medical Biological \\ Agency, Moscow, Russia \\ ${ }^{2}$ Civil Defence Academy EMERCOM of Russia, Moscow Region, Russia \\ ${ }^{3}$ Yaroslav-the-Wise Novgorod State University, Veliky Novgorod, Russia \\ ttx_2001@mail.ru
}

\begin{abstract}
One of the areas of occupational medicine is organizing the pre-shift medical examination of personnel of hazardous and extrahazardous industrial facilities, such as nuclear power plants. Appropriate medical control is not only permanent, but practically integrated into the technological process. The introduction of digital technologies at the stage of medical examination makes it possible to increase the efficiency of activities, reduce labour costs and opens up new opportunities for the constant accumulation of relevant information about the individual parameters of the employees' health status. The article analyzes the "digital twin" concept, substantiates the possibility of using the "Prognoz" [Forecast] hardware and software complex, used during preshift medical examinations, when creating digital copies of a nuclear power plant operator, discusses the development of individual criteria for permit to work according to the results of pre-shift control based on digital personal data processing. Digital twins of operators, which are in constant communication with their prototype, can be useful not only for ensuring the safety of nuclear industry production, but also when providing routine medical care, considering individual parameters of the employees' health status in the amount of the information collected. This approach makes it possible to form both digital twins of individual employees and digital twins of collectives (for example, entire shifts) with the subsequent formation of recommendations of both current and prognostic nature.
\end{abstract}

Keywords: industrial safety, prediction, model, medical digital twin, corporate health, occupational medicine, telemedicine platform

\section{INTRODUCTION}

Digital transformation is, no exaggeration, the mainstream of the industry technological development [1]. Modern industrial production uses digital and computer technology in all aspects of its work. As technologies are being introduced, more and more data is acquired in a digital form. Eventually, it becomes possible to create a complete enterprise description in a digital form - a digital copy (digital twin) [2].
Despite the fact that the topic of digital twins is not new, there is no generally accepted interpretation of this term at the moment [3]. To date (September, 2021), the Google search engine gives 690000000 links for the "Digital Twin" request and when typing, it is suggested to clarify the request by adding the subject area (software, technology, inlogistic, etc.) in the search box. Therefore, one can clearly see that the digital twins concept has not only come into application use, but also continues to actively develop, including in the healthcare field [4, 
5]. Patient digital twins are able to combine huge amounts of data to create digital copies of the physical environment and act as models to facilitate clinical decision-making [6-8]. Undoubtedly, this state of affairs predisposes to the search for the possibility of using digital technologies when developing measures aimed at preventing the contraction and progress of diseases, including professionally caused ones. We have not come across information reflecting the practical experience of creating a digital twin in industrial medicine in the literature available for research. Basically, reviews of literature data in this area are published (for example, [9]). In this regard, we propose our own example of the health control digitalization of nuclear industry personnel as a means of creating digital twins for consideration.

\section{MATERIALS AND METHODS}

The work used an analytical research method based on literature data, as well as the experience of using the "Prognoz" hardware and software complex (hereinafter - HSC) for pre-shift medical examination (hereinafter - PME) of workers at nuclear facilities. The purpose of this study was to find the possibility of using digital technologies applied for healthcare when organizing industrial production.

The objectives of the research included: consideration of the "digital twin in production" concept, analysis of the possibilities of using the digital twin industrial concept in occupational medicine, description of the environment features for the digital twins' functioning as applied to occupational medicine.

The "Prognoz" HSC has been developed by one of the authors of this article [10] and has been used from 2010 to the present; it identifies persons who at the time of the PME have deviations in physiological and psychophysiological parameters, which cause an increase in the likelihood of erroneous actions and disruptions in work. During the PME, the following actions are performed simultaneously: a) automatic measurement of blood pressure and heart rate; b) psychophysiological testing, which is a stress factor for an operator. Then an automated calculation of the individual rate is carried out and a classification conclusion on personnel permit to work is formed: "Approved" / "Not approved". The Omron M10-IT tonometer with software and a computer interface is integrated into the "Prognoz" HSC. During 2020, at one of the
NPPs in Russia, 71,174 PMEs were carried out using the "Prognoz" HSC in the group of NPP operators $(\mathrm{N}=364)$, all men, average age $43.8 \pm 6.2$ years. Daily PME was performed three times a day before the shift (from 00-00, 08-00 and 16-00 hours). The number of operators per shift varied from 64 to 68 people. To assess the functional state of the operators' central nervous system, an integral indicator of the stability of the functions systemic organization was used, which characterizes the stability of the ratio of the studied sensorimotor reactions to stimuli of various biological qualities. The built-in database allows you to save and view the results of each operator for the entire testing period and automatically form groups of people with unsatisfactory test results within a month (risk groups).

\section{RESULTS}

\subsection{Description of the "digital twin in production" concept}

Let us consider the definition of a digital twin, which can be viewed as a classic one, presented as a concept by Michael W. Grieves in 2003 [11].

The concept has three main parts: a) physical products in real space, b) virtual products in virtual space, and c) data and information connections that link virtual and real products together.

As it has been mentioned above, interest in the digital twin concept is steadily growing, new areas of its application are being found, and, accordingly, new interpretations appear. To illustrate the boundaries of the digital twin concept, A. Prokhorov and M. Lysachev created a special diagram (Figure 1).

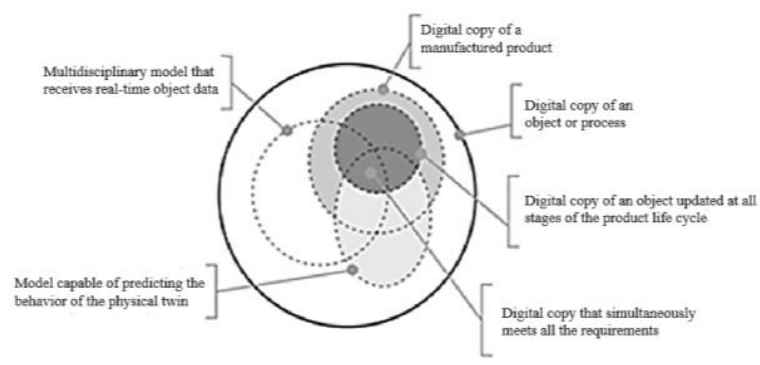

Figure 1. The boundaries of the "digital twin" concept in modern publications

Source: [3]

Nevertheless, despite different approaches to the digital twin definition, over the past years, a rather stable idea of this phenomenon has formed within 
the framework of industrial production, which resulted in the adoption of a number of preliminary standards of the Russian Federation in August 2020, one of which was PNST 429-2020 [12]. The document provides the following official definition of a digital twin: "A digital twin is a software and hardware complex that implements a complex dynamic model for researching and managing the activities of a socio-technical system." According to [12], the concept of production digital twins is described by the following scheme (Figure 2).

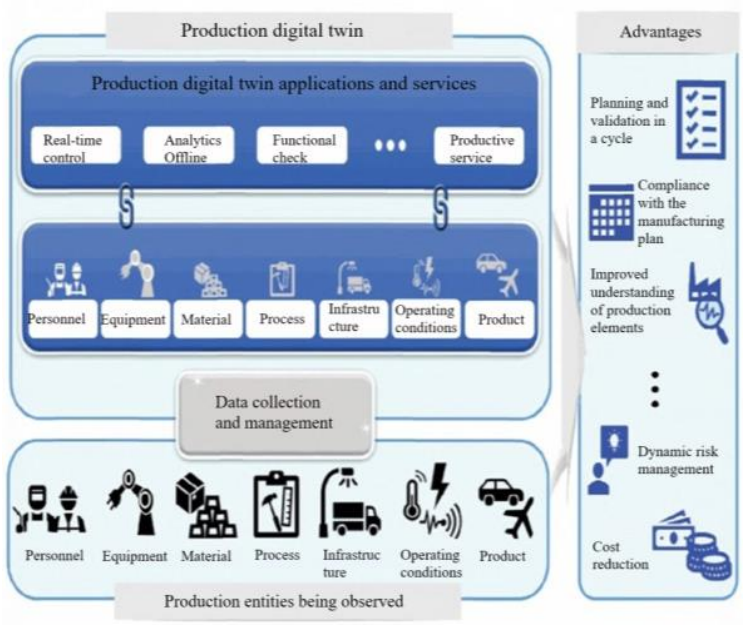

Figure 2. The concept of production digital twins Source: [12]

Therefore, the digital twin concept, according to A. Prokhorov and M. Lysachev, is based on obtaining new information about an object by processing its data in a virtual environment using a digital model. The main thing is also, as before, that each object can be represented in the form of a physical and virtual system, so that the virtual system reflects the physical, and vice versa. And despite the fact that the "digital twin" term appeared later, the concept of interaction of a physical product in the real world, its digital copy in the virtual world and the presence of an information connection between them, uniting virtual and material space, in fact, reflects the idea of digital twins. The model takes all changes that occur with a physical object into account, accumulates information about its behavior, and as it is refined it can more adequately describe and predict the behavior of a physical object [13-14]. Based on the updated model, recommendations can be formed to optimize the operation and maintenance of a real object [15].

When describing the digital twin in specific applications, one should start from the principles of the basic concept. Based on the concept and definition of a digital twin, in the "original sample (prototype) - digital twin" conjunction, the prototype is assigned the role of a kind of a "reference point", the centre of initial conditions and parameters, while the digital twin is constantly in focus, being a subject of research and an information source about the prototype expected behavior under various influences. The prototype can also play the role of a standard, a norm when studying, for example, destructive effects using a digital twin. In such a context, the prototype can be assigned a passive role, and the digital twin - an active one.

\subsection{Description of the digital twin for monitoring the health of NPP operators}

One of the most important components of production safety is the personnel's state of health [16], in this connection, the factory's sectorial doctor regularly carries out medical control using various methods.

For carrying out a psychophysiological examination of workers at nuclear facilities, both "Prognoz" and "PFS-Control" HSC can be used [17]. However, the latter complex does not record the indicators of the cardiovascular system function.

It is known that most of the monitored physiological parameters, such as blood biochemical parameters, have boundary values of the norms, while the values of others are not regulated. The latter include indicators of the central nervous system functional state.

One of the central tasks of assessing results in the course of the PME is the problem of individual differences. The difficulty lies in the fact that the variability of changes, for example, psychophysiological indicators, both in the same person and in different persons is enormous. It is important to note that the individual level of optimal physiological and psychological capabilities of the organism does not always coincide with the average statistical norm, since the same type of adaptation reactions proceed differently depending on the individual functional reserves. For example, the use of general norms when carrying out PME for operators at the age of twenty and fifty raises doubts about the effectiveness of diagnostics due to the large variability of health indicators. In our opinion, permit to work should be carried out only on the basis of each person's individual norms. The determination of the individual rate is formed within a certain time, when the operator performs his work without production disturbances and has no diseases during this period. Application of "Prognoz" HSC 
and a new way of organizing PME based on individual indicators has made it possible to personify the results of examinations.

In our case, the individual norm takes the operators' physiological and psychophysiological characteristics as well as daily fluctuations in the studied health parameters into account. It is calculated for each employee personally, being automatically formed for the twentieth time of passing the PME, provided that there are no disruptions in work and health during this period. As the results of passing the PME accumulate, in order to clarify the individual norm, its monthly recalculation is periodically carried out automatically. The diagnostic efficiency rate is $95.9 \%$.

The developed "Prognoz" HSC can be considered as one of the practical implementations of the digital twin concept presented above. So, a production operator is a physical object, according to the digital twin concept described by Michael W. Grieves, the results of his medical examination reflecting the physical state is a virtual object, the data entering the digital base is linking information (Figure 3).

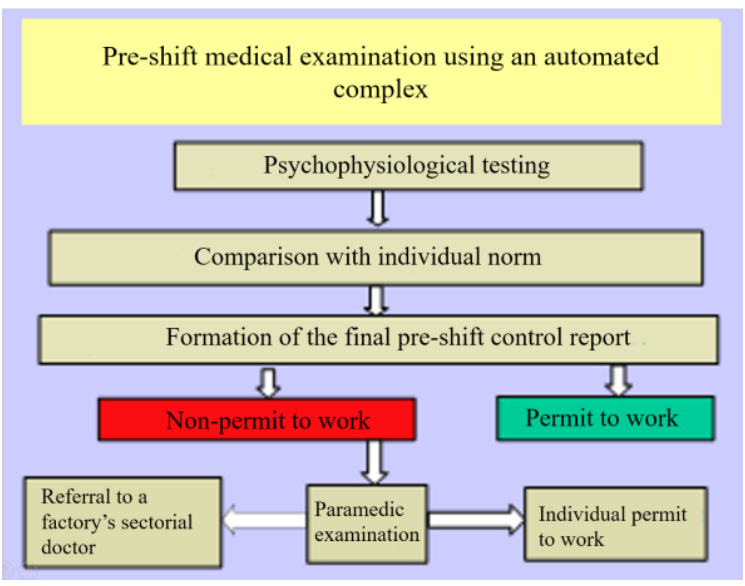

Figure 3. The scheme of forming a conclusion on professional competence using the "Prognoz" HSC Source: Compiled by the authors

According to one of the provisions of the standard [11], production digital twins can be implemented at various abstraction levels. In this case, the selected abstraction level, reflecting the employee's health indicators, the composition of which is dictated by the corresponding approved research methodology. It should be noted that in this case, the scheme of the digital twin concept, while remaining unchanged in its essence (Figure 4), can be considered in an extended version (Figure 5).

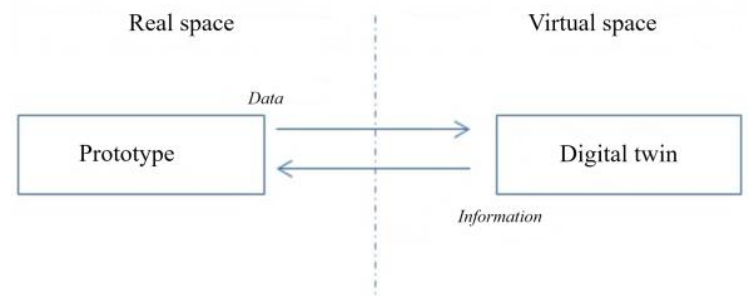

Figure 4. Basis of the digital twin concept scheme Source: Compiled by the authors

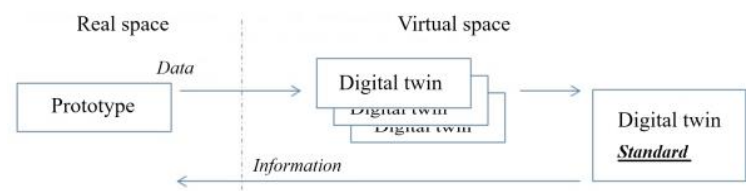

Figure 5. Extended version of the digital twin concept scheme

Source: Compiled by the authors

In other words, in the specified method for determining individual norms, the prototype not only supplies the initial data for its digital twin, but also, as a result of processing a set of digital twins, becomes a prototype for a digital twin-standard, the norms with which the prototype will be compared in the future. It should be especially noted that the digital twin-standard is such not only for the prototype, but also for other digital twins, since they are individual digital twins (health indicators) of the prototype, spaced in time. It is noteworthy, in our opinion, that in this interpretation the digital twinstandard itself acquires a passive role, performing the function of the carrier of the initial conditions for the prototype.

Digital twins (digital twin and digital twinstandard), performing the main function of control markers at a certain, fixed moment, remain so for solving a number of other tasks related to preserving and maintaining the level of employees' health. The digital twins as individual norms acquire a new function - the digital health standard, since they are designed for a healthy person, whose condition is confirmed by an appropriate medical examination.

\subsection{Medical information space - the environment for the digital twins' existence in the healthcare system}

As it was mentioned above, digital twins were designed primarily for the industrial production needs. The pioneers solved quite specific production problems and, accordingly, were limited by the production cycle, for which the "virtual space" term was quite enough to reflect it in the united 
production computer systems. However, with the development of computing systems and communication means, "virtual space" (in the aspect of the process of information technologies widespread use) has transformed into a "digital space" or "information space", which is defined as "a set of information resources created by the information sphere subjects, means of such subjects' interaction, their information systems and the necessary information infrastructure" [18]. In this context, the definitions "digital model" and "digital twin" given in [10] acquire new properties, going beyond the "hardware and software complex" or "computer", due to the multiple scalability of the latter's capabilities in the vastness of information spaces. However, the information space may well be limited by the framework of one computer.

To date, the medical information space has reached a development new level, primarily due to the adoption of a decree in 2018 on the creation of the Unified State Information System in the Healthcare Sector (USISHS) [19]. In addition, the development of departmental secure communication networks, telemedicine, the provision of the ability to maintain documentation in electronic form - all this fully testifies that the medical information space may well be considered as an environment for finding digital twins, obtained not necessarily within the space itself.

Therefore, the intermediate results of individual support processes for industrial production within the framework of the digital twin concept can provide new guidelines for research in a field that is not directly related to them, for example, in the field of industrial medicine.

\section{DISCUSSION}

The digital twin concept, originally created for the needs of industrial production, can have practical application in healthcare. The concept, even at the level of the proposed definitions of preliminary standards, is suitable for describing the stages of collecting and interpreting medical data in order to monitor the industrial personnel's health within the framework of PME. Moreover, the creation of digital twins in industrial medicine does not require almost any additional effort. On the contrary, the application of new concepts allows new complementary applications of established processes to be found. Additionally, it should be noted that changing the volumes of analyzed data and their interrelationships allows a flexible approach to the construction of digital twins with the necessary set of qualities that are relevant for solving specific problems.

In particular, the value of the stability indicator of the functions systemic organization, calculated according to the parameters of the two sensorimotor techniques, was used as a criterion for permit (nonpermit) to work in an automated complex. Its deviation from the average individual values within two sigma corresponds to the characteristics of the employee's psychophysiological state as satisfactory. In this case, "Prognoz" HSC issues an automatic report on permit to work. In case of deviation from the individual permit threshold of more than two sigma in one direction or another, an automatic report on non-permit to work is issued. The permit to work is based on a comparison of the values of the audio response speed and the approximate visual-motor reaction with the average values of the individual norm / speed of reaction.

However, given the Internet development, portable medical electronics, guided by the basic digital twin concept, a particular example can be used as a model for a successful solution of other medical problems.

The spread of the digital twin concept, in our opinion, will undoubtedly be facilitated by the development of the global medical information space.

\section{CONCLUSION}

Analyzing the literature and the results of our own experience when considering the "digital twin in production" concept, it has been found that information technologies allow related fields of medicine to exchange patients' data and personal information through the medical information space to obtain a complete picture of the human health state. The processes of digital transformation of industry and medicine together provide opportunities for obtaining new practical results, based on the consideration of existing technologies in a different context of practical application.

Therefore, the practical use of an automated complex for PME allows not only to make a report on the personnel's permit/non-permit, but also to make timely medical, organizational and other managerial decisions in order to reduce anthropogenic risk at hazardous and extrahazardous production facilities. The results of health control technology for the prevention of industrial accidents can be used to build individual trajectories of health indicators for individual population groups, creating 
conditions for the widespread introduction and development of individualized and personalized medical care.

\section{AUTHORS' CONTRIBUTIONS}

Leonid I. Baranov, Nikolay M. Tverdynin: research design development; final approval of the article version. Alexey N. Tsarev: obtaining data for analysis, interpretation of the obtained data; Leonid I. Baranov, Olga A. Tikhonova: research concept and manuscript text writing; Nadezhda I. Grishakina: review of publications on the topic of the article.

\section{REFERENCES}

[1] H. Yamani, W. Elsigini, "Digital Transformation and Industry 4.0", In "Innovative and Agile Contracting for Digital Transformation and Industry 4.0", IGI Global, 2021, pp. 1-17. DOI: http://doi:10.4018/978-17998-4501-0.ch001

[2] Q. Qi, F. Tao, Y. Zuo, D. Zhao, "Digital Twin Service towards Smart Manufacturing", Procedia CIRP, 2018, vol. 72, pp. 237-242. DOI: http://dx.doi.org/10.1016/j.procir.2018.03.103

[3] A. Prokhorov, M. Lysachev, "Digital twin. Analysis, trends, world experience" [Tsifrovoy dvoynik. Analiz, trendy, mirovoy opyt], In Ed. by A. Borovkov, Moscow: Alliance Print LLC, 2020. (In Russ.).

[4] J. Masison, J. Beezley, Y. Mei, H. Ribeiro, et al., "A modular computational framework for medical digital twins", in Proceedings of the National Academy of Sciences, 2021, vol. 118(20), p. e2024287118. DOI: 10.1073/pnas.2024287118

[5] A. Croatti, M. Gabellini, S. Montagna, A. Ricci, "On the Integration of Agents and Digital Twins in Healthcare", Journal of Medical Systems, 2020, vol. 44, p. 161. DOI: https://link.springer.com/article/10.1007/s10916 $-020-01623-5$

[6] B. Björnsson, C. Borrebaeck, N. Elander et al., "Digital twins to personalize medicine", Genome Med, 2019, vol. 12, p. 4. DOI: 10.1186/s13073-019-0701-3

[7] D.M. Eddy, L. Schlessinger, "Validation of the Archimedes Diabetes Model", Diabetes Care, 2003, vol. 26(11), pp. 3102-3110. DOI: http://dx.doi.org/10.2337/diacare.26.11.3102
[8] N.K. Chakshu, I. Sazonov, P. Nithiarasu, "Towards enabling a cardiovascular digital twin for human systemic circulation using inverse analysis", Biomechanics and Modeling in Mechanobiology, 2021, vol. 20(2), pp. 449-465. DOI: 10.1007/s10237-020-01393-6

[9] G. Paul, N.D. Abele, K. Kluth, "A Review and Qualitative Meta-Analysis of Digital Human Modeling and Cyber-Physical-Systems in Ergonomics 4.0.", IISE Transactions on Occupational Ergonomics and Human Factors, 2021, vol. 9(3-4), pp. 111-123. DOI: http://dx.doi.org/10.1080/24725838.2021.19661 30

[10] "A method for assessing the level of a person's central nervous system functional state on the basis of measuring the time of a person's indicative visual-motor reaction" [Sposob otsenki urovnya funktsional'nogo sostoyaniya tsentral'noy nervnoy sistemy cheloveka na osnove izmereniya vremeni oriyentirovochnoy zritel'no-motornoy reaktsii cheloveka]: RU 2 573340 C2. A61B 5/16; stated 29.04.2014; published: 20.01.2016 Bull. No 2 (In Russ.).

[11]M.W. Grieves, "Digital Twin: Manufacturing Excellence through Virtual Factory Replication", in "A Whitepaper by Dr. Michael Grieves”, LLC, 2014.

[12] "Preliminary national standard of the Russian Federation. Smart manufacturing. Production digital twins". Part 1. General provisions [Predvaritel'nyy natsional'nyy standart Rossiyskoy Federatsii. Umnoye proizvodstvo. Dvoyniki tsifrovyye proizvodstva". Chast' 1 . Obshchiye polozheniya]. PNST 429-2020 Federal Agency for Technical Regulation and Metrology [Federal'noye agentstvo po tekhnicheskomu regulirovaniyu i metrologii]. Moscow: Standardinform, 2020. (In Russ.).

[13] V. Warke, S. Kumar, A. Bongale, K. Kotecha, "Sustainable Development of Smart Manufacturing Driven by the Digital Twin Framework: A Statistical Analysis", Sustainability, 2021, vol. 13(8), p. 10139. DOI: https://doi.org/10.3390/su131810139

[14]F. Psarommatis, "A generic methodology and a digital twin for zero defect manufacturing (ZDM) performance mapping towards design for ZDM", Journal of Manufacturing Systems, 2021, vol. 59(2), pp. 507-521. DOI: https://doi.org/10.1016/j.jmsy.2021.03.021 
[15]D.A. Howard, Z. Ma, Z., C. Veje, A. Clausen, "Greenhouse industry 4.0 - digital twin technology for commercial greenhouses", Energy Inform, 2021, vol. 4, p. 37. DOI: https://doi.org/10.1186/s42162-021-00161-9

[16] Order of the Ministry of Health No. 749H, dated July 28, 2020, "On Approval of Requirements for Medical Examinations and Psychophysiological Examinations of Workers at Nuclear Facilities" [Prikaz Minzdrava ot 28 iyulya 2020 goda № 749n “Ob utverzhdenii trebovaniy $\mathrm{k}$ provedeniyu meditsinskikh osmotrov i psikhofiziologicheskikh obsledovaniy rabotnikov ob"yektov ispol'zovaniya atomnoy energii”] (In Russ.).

[17]M.Y. Kalinina, A.S. Kretov, A.N. Tsarev, M.A. Soloreva, E.A. Denisova, "Analysis of the Results of Psychophysiological Examinations of Personnel of Nuclear Facilities", Medical
Radiology and Radiation Safety, 2021, vol. 66(4), pp. 86-88. (In Russ.). DOI: 10.12737/1024-6177-2021-66-4-86-88

[18]Decree of the President of the Russian Federation No. 203 dated May 9, 2017, "On the Strategy for the Information Society Development in the Russian Federation for 2017-2030" [Ukaz Prezidenta RF ot 09.05.2017 № 203 “O Strategii razvitiya informatsionnogo obshchestva v Rossiyskoy Federatsii na 20172030 gody"]. (In Russ.).

[19]Decree of the Government of the Russian Federation No. 555 dated May 5, 2018 (as amended on June 11, 2021) "On the Unified State Information System in the Field of Healthcare" [Postanovleniye Pravitel'stva RF ot 05.05.2018 N 555 (red. ot 11.06.2021) "O yedinoy gosudarstvennoy informatsionnoy sisteme v sfere zdravookhraneniya"]. (In Russ.). 